\title{
Poder, Meios de Comunicação de Massas e Esfera Pública na Democracia Constitucional ${ }^{1}$
}

\author{
Power, Mass Media and Public Sphere in the Constitutional Democracy
}

\author{
Daniela Mesquita Leutchuk de Cademartori \\ Elias Jacob de Menezes Neto
}

Resumo: Este trabalho pretende analisar a relação entre a crise do Estado e o surgimento de poderes paralelos não regulados, com ênfase nos meios de comunicação de massas. Explicar-se-á o fenômeno de desintegração da opinião pública pelos meios de comunicação de massas. Será ressaltada a necessidade de regulamentação dos poderes midiáticos, em especial através de mecanismos que inibam a concentração proprietária dos meios de comunicação de massas e a sua relação com poderes econômicos e políticos. Concluir-se-á que o controle dos poderes midiáticos é meio hábil para reconstruir uma opinião pública legitimamente formada.

Palavras-chave: Meios de Comunicação de Massas. Esfera Pública. Democracia Constitucional. Poderes Selvagens.
Abstract: This paper aims to analyse the link between the crisis of the State and the emergence of unregulated parallel powers, with emphasis on mass media. It will be explained the disintegration of public opinion by mass media. It will be shown the need for regulation of media power, particularly through mechanisms that inhibit the ownership concentration of mass media companies and its association with economic and political power. It will be proposed that the control of media power is a valid expedient to rearrange a legitimately formed public opinion.

Keywords: Mass media. Public Sphere. Constitutional Democracy. Wild Powers.

\section{Introdução}

A opinião pública é essencial para o funcionamento das democracias ocidentais atuais. De maneira simples, é possível colocá-la como fun-

\footnotetext{
${ }^{1}$ Recebido em: 04/06/2012.

Revisado em: 21/03/2013.

Aprovado em: 20/03/2013.
} 
damento último do poder, afinal "Todo o poder emana do povo"2. Assim, o presente trabalho pretende, inicialmente, explicar as condições de existência, formação e possível desintegração da opinião pública e relacioná-la à teoria do Estado, possibilitando a adequação desta categoria para analisar o processo de tomada de decisões em sociedades democráticas e o aprofundamento da análise sobre os motivos da sua tão falada "crise". Para tanto, começará demonstrando a importância do conceito de esfera pública política habermasiana, sua desintegração ${ }^{3}$ e a sua conexão com a opinião pública e a democracia constitucional.

Instituição por excelência da esfera pública política e, portanto, de formação da opinião pública, os meios de comunicação de massas $(\text { media })^{4}$ sofreram modificações históricas que os transformaram em um

2 Como será visto, não se deve, por óbvio, confundir essa afirmação com a defesa de uma democracia majoritaria, em que a proteção dos direitos fundamentais não encontra barreiras constitucionais contra maiorias eventuais.

3 A opção pela palavra "desintegração", apesar de parecer fatalista, condiz com a terminologia utilizada por Habermas no original em alemão, como ocorre nos seguintes exemplos: "Die Desintegration der Wählerschaft als Publikum"; "[...] ein als Publikum desintegriertes Publikum [...]"; "[...] iner desintegrierten Öffentlichkeit die Kommunikation [...]” (1990, p. 320, 325, 345). No mesmo sentido, a tradução inglesa utiliza frequentemente a palavra "disintegration", como ocorre na expressão "disintegration of the Bourgeois Public Sphere" (1993, p. viii, xi, 14, 142, 175, 217). A edição em português mantém as traduções do original como "desintegração", apesar de traduzir "Der Zerfall" como "decadência", palavra que, na versão em inglês, foi traduzida como "disintegration".

4 Essa palavra, derivada do latim "medium", segundo o "Merriam-Webster Dictionary", significa, quando utilizada no plural, os membros da "mass media", ou seja, "dos meios de comunicação (jornais, rádio ou televisão), designados para alcançar as massas”. No mesmo sentido, o "Cambridge British English Dictionary" informa que a palavra media abrange "jornais, revistas, rádio e televisão quando considerados como um grupo". Como a língua inglesa, salvo no caso dos pronomes, não trabalha com gêneros gramaticais, adotou-se, neste trabalho, o gênero feminino, assim como ocorre com a palavra homófona "mídia", já comum no idioma pátrio. Observe-se que, ao contrário desta, capaz de ser empregada para designar os suportes físicos de difusão de informações, a palavra escolhida - media - é utilizada no inglês exclusivamente para se referir ao conjunto de veículos que compõem os meios de comunicação de massas. Para uma compreensão do conceito, ainda que com divergências, remete-se à leitura de John Brookshire Thompson (1998, p. 43-54). 
novo poder paralelo ao Estado, sendo necessário, pois, discutir o papel que eles exercem na esfera pública. A influência particularmente importante exercida pelo espaço televisivo na constituição da opinião pública, tanto a partir da ideia de homo videns (SARTORI, 1998) como a partir de uma realidade de controle desse espaço por parte do poder econômico e político no Brasil, justifica o enfoque que será dado durante o trabalho.

A existência do poder midiático não é negativa de per se, pois é natural, e até mesmo desejável, que existam poderes paralelos ao Estado. Esses poderes não devem, contudo, permanecer invisíveis ao controle do poder exercido legitimamente no Estado democrático de direito, pois tal situação viola uma das maiores promessas da democracia: a visibilidade e controle do poder - inclusive os não estatais. Para lidar com essa necessidade de visibilidade e controle do poder, o presente artigo irá trabalhar com a fusão dos conceitos de "poder selvagem", de Luigi Ferrajoli, e "poder invisível", de Norberto Bobbio.

Dentro do contexto dos invisíveis poderes selvagens - os meios de comunicação de massas são especialmente adequados ao conceito - o presente artigo irá discutir o problema da concentração dos meios de comunicação de massas no Brasil, dando ênfase à relação entre sua existência e a falta de pluralismo, verdadeiro "remédio" contra o abuso dos poderes. A democracia requer um nível constante de dissenso, que só pode ser garantido através da liberdade de expressão e comunicação, entendida amplamente, seja de maneira negativa, como dever de abstenção, seja de maneira positiva, como dever de ação estatal.

Não é possível falar em efetiva liberdade de expressão e comunicação em sistemas que permitem a concentração, invisibilidade e incontrolabilidade ${ }^{5}$ dos poderes midiáticos. Muito pelo contrário: o controle deixa de ser exercido sobre as media e passa a ser exercido por elas sobre a opinião pública num verdadeiro simulacro de esfera pública política.

Uma teoria do Estado democrático que se queira comprometida com os direitos fundamentais deve possibilitar a compreensão dos novos

\footnotetext{
${ }^{5}$ Como será explicado adiante, não se deve confundir controle dos meios de comunicação de massas com censura.
} 
poderes que colocam a democracia em perigo. É indispensável, portanto, para a proteção dos direitos fundamentais e para a contenção de poderes arbitrários, compreender que a crise na democracia constitucional refere-se à crise de funcionamento das estruturas de controle e fundamento do poder exercido pelo Estado e pela maior participação de determinados grupos privados.

Essa realidade de "controles invertidos", por fim, será exposta como um dos motivos da crise do Estado e do seu atual modelo representativo. Afinal, se aquele fundamento último do poder — a opinião pública - passa a ser manipulado por um poder invisível e incontrolável, soçobra a legitimidade do poder exercido pelo Estado e, portanto, sua própria legitimidade.

\section{A Desintegração da Opinião Pública}

Para Matteucci (1998, p. 842), a opinião pública é uma expressão que carrega duplo sentido: na sua formação, é "pública" por ser originada fora da esfera privada, ou seja, no debate público de ideias; no seu objeto, é pública por tratar de assuntos de interesse de uma determinada comunidade. Para Bobbio (1997, p. 90), é "[...] a opinião relativa aos atos públicos, isto é, aos atos próprios do poder público”. Para Habermas (2003), ela é o conjunto de discussões públicas depois que o público, por formação e informação, torna-se apto a elaborar uma opinião bem fundamentada sobre assuntos de relevância coletiva.

Como “opinião", é expressão de juízo de valor, sempre discutível e cambiante, permitindo, portanto, a discordância e o dissenso. Como "pública", isto é, relativa ao caráter político do homem, é plural, dada a impossibilidade de existir espaço para apenas uma única verdade política. Por ser mera opinião (doxa), afirma Matteucci (1998, p. 842), não corresponde necessariamente à verdade (episteme), mas ao pensamento racionalmente forjado através do debate crítico e bem informado.

Sua função é permitir a participação ativa dos cidadãos na esfera pública política através da manifestação e divulgação das próprias ideias e, portanto, está intimamente ligada ao pluralismo e à liberdade de ex- 
pressão e comunicação. Nesse sentido, é o pensamento corroborado por Luigi Ferrajoli, para quem o exercício dos direitos políticos - logo, no âmbito da esfera pública política — pressupõe que "[...] la formazione di opinioni politiche e di una pubblica opinione solo può provenire dalla libera espressione del pensiero, dal dibattito pubblico e da un'informazione independente [...] e lo sviluppo di movimenti di opinione e di opposizione". (2007b, p. 337)

Seu surgimento coincidiu com o do Estado moderno, pois dependeu, como visto, de uma sociedade civil burguesa distinta - mas simultaneamente dentro - do Estado e organizada numa esfera pública política (HABERMAS, 2003, p. 46), permitindo, assim, a formação de opiniões não individuais de grupos interessados em exercer o controle do poder estatal; todavia, foi condenada pelos teóricos do absolutismo por introduzir a semente da anarquia e da corrupção no Estado. Tais críticas reapareceram, segundo Matteucci (1998, p. 844), com Hegel. Para o filósofo alemão, a opinião pública seria um conjunto de opiniões individuais que, somadas, não seriam capazes de expressar a opinião comum do grupo. Outras críticas feitas diziam respeito ao conhecido perigo do despotismo da maioria ou do conformismo de massa, que resultariam na crise da opinião pública e, consequentemente, no colapso do diálogo racional e na impossibilidade de estabelecimento das condições de "[...] diálogo ideal do iluminista com seu público pretendido por Kant" (MATTEUCCI, 1998, p. 845). Com o advento das novas tecnologias de comunicação de massas e da formação de oligopólios com fortes poderes econômicos ligados às media, as críticas parecem razoáveis, pois essas novas situações dificultam o desenvolvimento da liberdade de expressão e comunicação, do pluralismo de ideias e da pluralidade de órgãos de comunicação autônomos, condições essenciais para a evolução de uma opinião pública livre e racionalmente fundada.

Coloca-se a questão sobre a desintegração da opinião pública (HABERMAS, 2003) e da esfera pública, pois elas são tão importantes que, na impossibilidade de existirem, precisam ser simuladas. A crise da democracia representativa - e, consequentemente, da democracia constitucional — é acentuada por uma opinião pública débil e artificial, pois, à 
medida que as funções políticas da esfera pública são fragilizadas, é enfraquecido o parlamento como órgão do Estado na esfera pública.

Jürgen Habermas, assim como os marxistas de modo geral, partindo de uma avaliação geral negativa da comunicação de massa e de seu impacto, afirmou que a publicidade como princípio crítico, a abertura das questões públicas à discussão por cidadãos interessados, deu lugar a uma opinião pública manipulada. (THOMSON, 1996)

Logo, a ampliação da esfera pública pelas técnicas dos novos meios de comunicação de massas resulta, paradoxalmente, na desintegração da opinião pública, pois “"[...] o mundo criado pelos meios de comunicação de massas só na aparência ainda é esfera pública [...]" (HABERMAS, 2003, p. 202). O público midiatizado, integrante de uma opinião pública desintegrada numa esfera pública incrivelmente ampliada, é "[...] incomparavelmente mais citado de diversos modos e com maior freqüência para fins de aclamação pública, mas, ao mesmo tempo, ele está distante dos processos de exercício do poder [...]" (HABERMAS, 2003, p. 212), o que faz com que tenha a falsa consciência de que contribui responsavelmente para a formação da opinião pública. Os meios de comunicação de massas passam a servir apenas para possibilitar um entretenimento ao mesmo tempo agradável e facilmente digerível, que tende a substituir a captação totalizadora do real por aquilo que está pronto para o consumo e que mais desvia para o consumo impessoal de estímulos destinados a distrair do que leva para o uso público da razão. (HABERMAS, 2003, p. 202)

O público-alvo também é diferenciado nessa esfera pública ampliada. Enquanto as media tradicionais da esfera pública literária atingiam geralmente as camadas sociais com maior poder econômico, na atualidade a situação passa a ser oposta, e a penetração e influência das media é mais forte nos círculos menos favorecidos, especialmente em virtude do barateamento da tecnologia necessária e do menor tempo de escolaridade associado a determinados públicos. A engineering of consent (HABERMAS, 2003), que pode ser aqui traduzida como a arte de manipular o público, permite a inserção de ideias no imaginário social, além da manutenção e transmissão de memes convenientes ao establishment. Coloca-se em risco a racionalidade do debate político gerado a partir de informações 
produzidas com a finalidade específica de desinformar. A formação artificial de um consenso não leva a sério a opinião pública iluminista, pois o interesse geral desaparece à medida que determinados interesses privados, privilegiados com o acesso aos meios de comunicação de massas, ignoram a concorrência aberta de ideias (HABERMAS, 2003). A televisão, meio peculiarmente importante de comunicação de massas, contribui sobremaneira para a despolitização e deseducação massiva, a desintegração da opinião pública e a primazia dos interesses privados através do enfraquecimento da relevância política da opinião pública, pressuposto necessário da democracia. (FERRAJOLI, 2011)

\section{Os Invisíveis Poderes Selvagens Midiáticos}

A democracia, denuncia Sartori (1998, p. 68), é definida frequentemente como "governo de opinião". Essa definição parece adequada ao aparecimento da videopolítica, fenômeno que faz com que o "povo soberano" fundamente suas opiniões de acordo com o que a televisão os induz a acreditar. Para conduzir a opinião pública (SARTORI, 1998), fabricar (CHOMSKY, 2003) ou engenhar (HABERMAS, 2003) o consenso, o poder da imagem assume papel central na política contemporânea.

A opinião pública está intimamente relacionada à visibilidade do poder em uma democracia, ou seja, “[...] para constituir-se uma opinião pública nos moldes apontados é imprescindível que se dê publicidade aos debates e decisões político-jurídicos" (BOLZAN DE MORAIS; STRECK, 2010, p. 193). Os autores concordam com a afirmação de Norberto Bobbio (1997) de que a maior ou menor relevância da opinião pública depende também da acessibilidade que as massas têm a informações relativas aos atos públicos e atos decisórios do Estado.

Na sociedade midiática de massas, a opinião pública é forjada na "cultura global pasteurizada". Ela é moldada, domesticada, controlada, infantilizada e incapacitada de distinguir os próprios interesses dos alheios, defendendo-os como se fossem seus e tendo a capacidade crítica usurpada pelas media (BOLZAN DE MORAIS; STRECK, 2010, p. 193). Desde o início do século XX, a indústria das relações públicas dedicou 
incansáveis esforços para controlar o único perigo sério: a mente popular. De acordo com Chomsky (2003, p. 454-455), uma importante figura da indústria das relações públicas dos EUA, Edward Bernays, chega ao ponto de afirmar que "[...] a manipulação consciente e inteligente dos hábitos e opiniões organizados das massas é um componente importante da sociedade democrática". Esse controle da opinião pública é mais importante para governos livres e populares do que para os Estados despóticos e militarizados, pois, enquanto nestes ocorre o controle da opinião pública pela coação, nos Estados livres há diminuição do uso da força física e, por isso, é necessário "[...] pôr o público em seu lugar [...]" através de outros meios de dominação. (CHOMSKY, 2003, p. 444)

\subsection{O Poder Invisível}

De maneira geral, o descumprimento das promessas da democracia, de acordo com Norberto Bobbio, não significa degeneração do sistema democrático, pois não estavam destinadas a serem cumpridas, consistindo apenas em adaptações do ideal democrático à realidade e à "[...] inevitável contaminação da teoria quando forçada a submeter-se às exigências da prática [...]” (BOBBIO, 1997, p. 10). A exceção é a “[...] sobrevivência (e a robusta consistência) de um poder invisível ao lado ou sob (ou mesmo sobre) o poder visível [...]" (BOBBIO, 1997, p. 10), pois, apesar de ser possível definir a democracia de diversas maneiras flexibilizando suas características, é impossível fazê-lo sem incluir a visibilidade (transparência) do poder. A grande proposta dos primeiros regimes democráticos foi desvelar o núcleo duro e oculto do poder exercido por pequenos grupos.

O problema consiste, portanto, na ocultação do poder. Essa foi, inclusive, uma das razões de superioridade do regime democrático em relação ao Estado absoluto, em que eram defendidos os poderes ocultos (arcana imperii). Nas palavras de Bobbio (1997, p. 11), “[...] enquanto a presença de um poder invisível corrompe a democracia, a existência de grupos de poder que se sucedem mediante eleições livres permanece [...] como a única forma na qual a democracia encontrou a sua concreta atuação".

Segundo Bobbio (1997, p. 29-30), “[...] uma ação que sou forçado a manter secreta é certamente não apenas uma ação injusta, mas so- 
bretudo uma ação que se fosse tornada pública suscitaria uma reação tão grande que tornaria impossível a sua execução [...]”. Com isso, ele reafirma a fórmula kantiana de que são injustas todas as ações que se referem ao direito de outros homens cujos princípios não suportam a publicação. (KANT, 2006)

O controle público - no desvelamento - do poder passa a ser de vital importância na nossa sociedade, na qual são abundantes os meios tecnológicos à disposição daqueles que controlam as media. Os meios de comunicação de massas, quase sempre associados ao poder político ou econômico, possuem aparato tecnológico e técnicas para fazer chegar seu conteúdo em todos os lugares do Brasil com capacidade de penetração e persuasão inimagináveis.

\subsection{Poderes Selvagens}

Ao contrário do que foi colocado no início deste artigo e na Constituição Federal brasileira, no mundo real, nem todo poder emana do povo. À situação, José Luis Bolzan de Morais (2002) dá o nome de "crise funcional do Estado". Segundo o autor, a multiplicidade dos loci de poder resulta na perda de centralidade e exclusividade do Estado e pode ser sentida tanto pelos órgãos responsáveis pelas funções estatais típicas do modelo clássico de tripartição das funções como também por órgãos que exercem outras funções estatais de natureza regulamentar ou decisória. $\mathrm{O}$ Estado perde parte do seu poder coercitivo frente aos poderes extraestatais, tendo dificuldades em fazer valer suas decisões.

Os poderes selvagens, expressão utilizada por Luigi Ferrajoli (1995, 1998, 2007a, 2007b, 2011), são formas de poder incontroláveis e ilimitadas e que, por isso, podem prejudicar ou subjugar os poderes jurídicos e a ordem do Estado de direito. Essa denominação "[...] chiaramente allude a quella 'libertà selvaggia e sfrenata' di cui parla Kant nella Metafisica dei costumi come della condizione sregolata propria dello stato di natura, ossia in assenza del diritto, opposta a quella propria dello 'stato giuridico' o di diritto" (FERRAJOLI, 1998, p. 11) e distingue quatro classes de poderes selvagens, sendo a mais pertinente ao presente estudo o poder privado do tipo extralegal, que é "[...] i macropoteri economici che, in assenza di 
limiti e di controlli legali, tendono a svilupparsi secondo dinamiche proprie [...]”. (FERRAJOLI, 1998, p. 14)

A única legitimidade e regulamentação desses poderes, atualmente em franca expansão graças à tendência atual ao desmantelamento da esfera pública, são aquelas do mercado desregulamentado e selvagem. Tais poderes, como extralegais, não respeitam a legalidade e não estão sujeitos a nenhum poder político ou jurídico. São, assim, "[...] poderes de hecho, cuya sola existencia testimonia en ocasiones la prevalencia de la fuerza sobre el derecho [...]" (FERRAJOLI, 1995, p. 933) e podem ser classificados em macropoderes e micropoderes selvagens, este último de relevante importância para o presente estudo.

Os micropoderes selvagens se desenvolvem no âmbito das funções e instituições jurídicas abandonadas a dinâmicas substancialmente livres e incontroláveis, que atuam fora das instituições jurídicas vigentes, ou seja, em razão da "[...] la crisi simultanea della ragione giuridica e politica e della capacità regolativa del diritto, di fronte alla crescita di poteri selvaggi extra-statali che sfuggono al suo controllo [...]" (FERRAJOLI, 2007a, p. 4). Os poderes exercidos pelo chefe da família e pelo superior hierárquico, por exemplo, atuam de maneira extralegal. Os exercidos informalmente com base na opressão econômica ou em ambientes abertamente criminosos são exemplos de micropoderes selvagens ilegais. (FERRAJOLI, 1995)

Ainda que seja muitas vezes difícil estabelecer a divisão entre poderes extralegais e ilegais, os poderes selvagens geralmente atuam tanto de maneira deliberadamente ilegal como, através da distorção das regras existentes, dentro da esfera de legalidade estabelecida. "Violencia, dinero, coacciones económicas [...] forman en todo caso el cemento de estas relaciones, donde la lesión del valor de la persona puede producirse al margen de cualquier posible garantía jurídica" (FERRAJOLI, 1995, p. 933). Assim, se os poderes jurídicos são a base das desigualdades formais, os extrajurídicos, incontrolados e ilimitados, alicerçam as desigualdades de um tipo muito mais profundo: sociais ou substanciais. Também vale para os poderes privados a assertiva de Montesquieu de que "[...] todo homem que possui poder é levado a dele abusar; ele vai até onde encontra limites. 
[...] Para que não se possa abusar do poder, é preciso que, pela disposição das coisas, o poder limite o poder" (1996, p. 166). Logo, é possível concluir que o poder tem o efeito de produzir desigualdades e relações de poder baseadas na sujeição do mais fraco, o que torna poder e direitos fundamentais antagônicos. (FERRAJOLI, 1995, p. 933-934)

Os poderes extrajurídicos, por estarem fora do controle tradicional, são tendencialmente absolutos. Ainda que o sistema esteja organizado como Estado de direito, o absolutismo dos poderes selvagens está diretamente relacionado à quantidade de espaços criados por poderes extrajurídicos — ou de poderes conformes com a mera legalidade — na sociedade civil. Obviamente, a realidade não permite a normatização plena de todo exercício de poder, sendo necessárias, segundo Ferrajoli (1998, p. 934), garantias essenciais para que um poder, quando, por força das suas funções sociais, não puder ser suprimido, seja, pelo menos, o mais limitado possível pela lei. Tal perspectiva é plenamente aplicável aos meios de comunicação de massas que, em razão da sua importância e poder, devem ser fortemente limitados pela lei ${ }^{6}$. Os poderes privados, assim como os públicos, devem ser submetidos ao controle, legitimação e justificação formal e substancial na democracia. Diminuir os poderes selvagens é maximizar as liberdades e os direitos fundamentais.

\subsection{Comunicação Política e Concentração dos Meios de Comunicação de Massas}

Nos regimes democráticos ${ }^{7}$, a comunicação política tende a ocorrer constantemente entre as elites e a opinião pública das massas populares. Funciona como forma de as elites solicitarem apoio ao povo ou, mais raramente, fazendo o caminho inverso, ou seja, das massas para as elites. Contudo, o fluxo comunicativo fica prejudicado em virtude da desinte-

\footnotetext{
6 Adiante-se, contudo, que a "forte limitação legal" nada tem a ver com censura, mas, como será visto, com o controle sobre o exercício indiscriminado de poder econômico e político nos meios de comunicação de massas tendo por fim último o pluralismo político. 7 Angelo Panebianco faz uma análise pormenorizada dos fluxos de comunicação (seguindo a descrição de Richard Fagen) nos regimes democráticos, mas também nos totalitários e nos autoritários (PANEBIANCO, 1998). Recomenda-se a leitura integral do verbete "comunicação política" na obra mencionada.
} 
gração da esfera pública política produzida pela simulação, debilitação e degradação da opinião pública, fenômenos patrocinados pela concentração dos meios de comunicação de massas.

Segundo Angelo Panebianco (1998), a comunicação política é o conjunto de mensagens que condicionam a atividade de um sistema político, das formações de demandas e respostas dadas pelo sistema. Para o autor, ela está ligada "[...] à sociologia das comunicações de massa, é própria das teorias que se concentram nos efeitos de um acesso desigual aos recursos de comunicação sobre a distribuição do poder político dentro dos diversos grupos organizados". (PANEBIANCO, 1998, p. 201)

Assim, a comunicação política está presente em todo o comportamento humano com a função de manter e adaptar o sistema político. Os contatos informais entre os membros de um determinado grupo seriam a forma mais comum de comunicação política, com destaque para o papel especial dos líderes de opinião na formação da opinião pública. Contudo, uma importante modificação ocorreu nos sistemas modernos: a introdução dos meios de comunicação de massas, especialmente os eletrônicos. A transferência do eixo da comunicação política para esses novos meios de comunicação torna o tipo, a qualidade e a frequência das mensagens transmitidas pelas media decisivos "[...] para a formação das atitudes da opinião pública e, consequentemente, para o tipo de pressões que ela exerce sobre os centros decisórios do sistema político" (PANEBIANCO, 1998, p. 201), além de ter transformado o ocultamento em fenômeno inerente à comunicação política. (BOBBIO, 1997, p. 101)

O problema, como mencionado anteriormente, ocorre com a confusão entre poderes econômico, político e midiático. Não de maneira incomum, poderes econômicos e políticos fundem-se nos meios de comunicação de massa como forma de fortalecimento. Segundo Norberto Bobbio (1997, p. 103), a classe política

[...] exerce o poder não mais apenas através das formas tradicionais da lei, do decreto legislativo, dos vários tipos de atos administrativos - que, desde quando existe um regime parlamentar e um estado de direito (um estado, entenda-se, em que os atos da administração pública são submetidos a um controle jurisdicional), co- 
meçaram a fazer parte da esfera do poder visível -, mas também através da gestão dos grandes centros de poder econômico (bancos, indústrias estatais, indústrias subvencionadas, etc.), da qual acima de tudo extrai os meios de subsistência dos aparatos dos partidos, dos aparatos dos quais por sua vez extrai, através das eleições, a própria legitimação para governar.

Nesse sentido, Bobbio (1997, p. 102) propõe a existência de subgovernos e criptogovernos, bem como esclarece a necessidade de uma - inexistente - teoria para estudá-los. Como exemplo desse invisível e selvagem exercício de poder, Luigi Ferrajoli (2007a, 2007b, 2011) traz o poder midiático proporcionado pela concentração dos meios de comunicação de massas. Para ele, a concentração proprietária e a confusão dos poderes políticos e midiáticos, gerada pelo controle das media pelos titulares de poderes políticos e econômicos, coloca em contraste outra separação de poderes produzida pela modernidade, a saber, "[...] la de poder y saber y, precisamente, de poderes, tanto públicos como privados, e información" (FERRAJOLI, 2011, p. 54). Nisso resulta a inversão da relação entre media e poderes públicos: a imprensa livre não controla mais os poderes públicos, pois estes passam a controlar aquela. A informação fica à mercê do entrelaçamento entre poderes públicos e privados, fundidos nos meios de comunicação de massas.

A apropriação privada da liberdade de comunicação e expressão (FERRAJOLI, 2007b) permite que o poder econômico e o político, munidos dos aparatos tecnológicos adequados, manipulem a comunicação política de tal maneira que os meios de comunicação de massas podem ser considerados um quarto poder, potencialmente danoso para a democracia, o qual, na atualidade, encontra-se completamente livre para agir sob o manto de uma compreensão distorcida do que seja a "liberdade de expressão", que, da forma como é pregada, serve unicamente para "blindar" os interesses dos controladores das media. O que havia sido concebido como nobre e elevado, parafraseando Bobbio (1997), é transformado em matéria bruta, ou pior, em protetor da torpeza. A concentração dos meios de comunicação de massas converte, assim, a liberdade de expressão e comunicação numa "[...] libertà selvagge e alla legge del più forte la cui 
soppressione, secondo il paradigma hobbesiano, è la prima ragione sociale dell'artificio giuridico". (FERRAJOLI, 2007a, p. 759)

A liberdade de expressão e comunicação passa a ter seu exercício constrangido, especialmente na sua "[...] dimensione attiva quale 'libertà di' o libertà-facoltà, virtualmente vanificata dai poteri economici consistenti nella proprietà e nella disponibilità dei mezzi di informazione e di manifestazione e diffusione del pensiero" (FERRAJOLI, 2007b, 338). As media são bens patrimoniais submetidos ao direito de propriedade e da autonomia civil da livre iniciativa econômica e, sem a devida limitação, podem restringir severamente direitos de liberdade, tornando os meios de comunicação de massas inacessíveis ao público e concentrando-os segundo a dinâmica do mercado. (FERRAJOLI, 2007b, p. 338)

Misturam-se, assim, direitos fundamentais de natureza diversa. Nas palavras de Luigi Ferrajoli, confundem-se “[...] la libertà d'informazione, che è un diritto di libertà, la libertà d'impresa giornalistica, che è un diritto-potere di autonomia, e la proprietà dei mezzi d'informazione, che è un diritto patrimoniale reale" (2007b, p. 338). Como resultado dessa confusão, os detentores do poder midiático passam a ser também os titulares principais da liberdade de expressão e comunicação, fato que contraria sua própria natureza na democracia constitucional, que deve garantir a livre expressão a qualquer cidadão, permitindo o pluralismo de ideias e garantindo a livre comunicação política. A ideia de que o direito fundamental de manifestar o próprio pensamento dependa de fatores econômicos e de direitos civis ignora sua básica hierarquia infraconstitucional, pois o exercício de direitos fundamentais não pode depender dos meios econômicos que possui seu titular. Além disso, Ferrajoli (2007b, p. 339) lembra que a liberdade de expressão de pensamento diz respeito ao ser humano que escreve ou pronuncia a palavra, não ao proprietário dos meios de comunicação de massas. O resultado dessa confusão jurídica e subordinação da liberdade de expressão e comunicação é a geração de um círculo vicioso que impede seu avanço jurídico, violadora do pluralismo de informações. (FERRAJOLI, 2007b)

Assim, é necessária a defesa da liberdade de expressão e comunicação e, consequentemente, do pluralismo político através do questiona- 
mento sobre a pluralidade dos proprietários dos meios de comunicação de massa. Esse poder das media passa a ser perigoso quando limitado a pequenos grupos econômicos e políticos, pois adquirem a possibilidade de reprimir e silenciar as vozes dissidentes. (FERRAJOLI, 2007b, p. 341)

O leitor poderia se questionar sobre a possível superação da televisão por outros meios multimídia, especialmente pela internet. Sobre o assunto, Sartori (1998, p. 53-61) afirma que, de fato, a tecnologia presente nos computadores é superior à da televisão. No entanto, não se deve presumir que esta seja inferior: são instrumentos que oferecem produtos diferentes. Assim como o rádio não foi anulado pela invenção da televisão, esta não parece caminhar para superação pela internet. Por isso, continuará sendo o centro das media, tendo em vista que a internet produz "saturação", e é mais confortável ver passivamente, como ocorre na televisão, do que interagir ativamente, como ocorre com a internet. Por suas próprias características, a televisão mostra imagens que remetem à "realidade", enquanto o ciberespaço é, como o próprio nome sugere, "virtual", "imaginário". Acrescente-se a isso a situação de que, em muitas sociedades industriais do Ocidente, os adultos passam uma média de 25 a 30 horas semanais assistindo à televisão, e esta se transformou na mais importante fonte de informação sobre os eventos nacionais e internacionais. (THOMSON, 1996, p. 114)

\section{Processo Desconstituinte e Crises do Estado}

O "processo decostituente", nas palavras de Luigi Ferrajoli (2005, 2010, 2011), é a desconstitucionalização do sistema jurídico-político, ou seja, o esvaziamento do núcleo fundamental de uma constituição. Ocorre através da sucessão de ações, geralmente tomadas pelos poderes selvagens, contra a democracia representativa e que colocam em perigo direitos e garantias fundamentais ínsitos ao constitucionalismo contemporâneo. Para José Luis Bolzan de Morais (2002), é um processo de fragilização da Constituição, de sua transformação em programa de governo, da colonização econômica da política e da tentativa "neoliberal" de conside- 
rar a Constituição um instrumento impeditivo do desenvolvimento econômico.

Dois processos paralelos concorrem para o fenômeno. O primeiro, de caráter institucional, manifesta-se no sistema político com sucessivos ataques à democracia representativa através da

[...] la explícita pretensión de la omnipotencia de la mayoría y la neutralización de ese complejo sistema de reglas, separaciones y contrapesos, garantías y funciones e instituciones de garantía que constituye la sustancia de la democracia constitucional. (FERRAJOLI, 2011, p. 21)

A ideia por trás desse processo é que o consenso popular, não importa a que custo seja obtido, é a única fonte de legitimação do poder e, portanto, capaz de legitimar qualquer abuso e deslegitimar qualquer opinião dissidente. Como resultado,

[...] el edificio de la democracia constitucional resulta minado de raíz en su totalidad: porque no se soporta el pluralismo político y constitucional; por la desvalorización de las reglas; por los ataques a la separación de poderes, a las instituciones de garantía, a la oposición parlamentaria, a la crítica y a la prensa libre; en definitiva, por el rechazo del paradigma del estado constitucional de derecho como sistema de vínculos legales impuestos a cualquier poder. (FERRAJOLI, 2011, p. 21-22)

O segundo processo tem lugar no plano social e cultural, "[...] con la eliminación de los valores constitucionales en las conciencias de una gran parte del electorado: por indiferencia, por falta de sentido cívico o por el cambio de la propia concepción de la democracia en el imaginario colectivo" (FERRAJOLI, 2011, p. 22). A opinião pública, anestesiada pelas media, renuncia à liberdade política. Sobre isso, Ferrajoli (2007b, p. 337) afirma que "[...] la disinformazione, la passivizzazione, l'apatia e l'indifferenza politica risultanti dalla rinuncia o dalle difficoltà frapposte all'esercizio di tali libertà, e perciò dalla loro ineffettività, sono fattori di indebolimento e di deperimento della democrazia". 
No prefácio da tradução espanhola de "Poderes Salvajes", Perfecto Ibáñez consegue sintetizar bem o problema:

[...] bien diagnosticado de auténtico proceso «deconstituyente», como cifrado en el vaciamiento de la democracia política y reflexivamente orientado a la simultánea desactivación de las estructuras constitucionales básicas. Todo sobrevolado por una política cultural, mediáticamente muy bien instrumentada, dirigida de forma sistemática y -iay!- con éxito al envilecimiento y la insensibilización de la opinión. (FERRAJOLI, 2011, p. 15)

São colocados três aspectos caracterizadores do processo desconstituinte. $\mathrm{O}$ primeiro é a personalização e verticalização da representação política. A difusão mundial do modelo presidencialista e do sistema eleitoral majoritário tende a personalizar o poder, facilitando o surgimento de um "governo do homem", ou seja, de governos antidemocráticos, pois, nas palavras de Bobbio (1997), a democracia é o governo das leis por excelência. De acordo com Ferrajoli (2010), a concepção desses modelos subestima a representação da pluralidade de interesses sociais no debate parlamentar e identifica o chefe do poder executivo como representante máximo de uma suposta vontade popular, o que resulta no enfraquecimento dos partidos políticos como lugar e instrumento de agregação e representação dos diversos interesses sociais conflitantes. Na precisa crítica de Ferrajoli (2011, p. 51), a existência de um chefe do executivo - ou de qualquer poder - carismático é incompatível com a democracia e demonstra o enfraquecimento das suas dimensões política, representativa e constitucional. Trata-se, portanto, de um retrocesso da democracia política, pois é impossível que qualquer concentração de poder seja capaz de representar a vontade política de uma nação ${ }^{8}$.

O segundo aspecto é a progressiva confusão e concentração de poderes que, muito além da clássica teoria tripartite, viola um dos fundamentos da democracia: a separação entre a esfera pública, sintetizada na

\footnotetext{
8 É necessário deixar claro que, apesar de Ferrajoli se referir ao modelo berlusconiano, as críticas relativas à personalização e verticalização da representação política são plenamente aplicáveis em outros lugares do mundo, em especial no Brasil e na América Latina.
} 
liberdade de expressão e comunicação, e a esfera privada, relativa ao poder econômico dos proprietários dos meios de comunicação de massas. Essa violação, facilitada pela ausência de limites e regulação dos poderes selvagens, impossibilita a existência do pluralismo das fontes de informação, essencial para a comunicação política e para a democracia. Os poderes selvagens tornam-se, assim, onipotentes e passam a ditar as regras do jogo. O terceiro e último aspecto colocado por Ferrajoli (2010), consequência imediata do segundo, é o rebaixamento da esfera pública, da legalidade e da constitucionalidade, bem como a desvalorização do Estado de direito como sistema de limites e vínculos impostos aos poderes.

O tema "crise do Estado" certamente remonta ao surgimento do próprio Estado. Especialmente nas últimas décadas do século $\mathrm{XX}$, os paradigmas orientadores dessa construção teórica moderna foram sendo paulatinamente minados por incompatibilidade com os interesses dominantes (BOLZAN DE MORAIS, 2002). O referido autor divide a crise estatal em cinco subtipos diferentes: conceitual, estrutural, constitucional, funcional e política. Para fins do presente trabalho, serão analisadas apenas as duas últimas: a funcional e a política.

A crise funcional confunde-se com o primeiro processo desconstituinte exposto anteriormente — de índole institucional — e diz respeito à perda de centralidade e exclusividade do Estado no exercício do poder, especialmente em decorrência da multiplicação dos loci de tomada de decisões legislativas, executivas ou jurisdicionais (BOLZAN DE MORAIS, 2002, p. 51). Apesar de não tratar da crise nessa perspectiva, Bobbio explica que essa descentralização do poder diz respeito à forma através da qual a classe política o exerce

[...] não mais apenas através das formas tradicionais da lei, do decreto legislativo, dos vários tipos de atos administrativos — que, desde quando existem um regime parlamentar e um estado de direito (um estado, entenda-se, em que os atos da administração pública são submetidos a um controle jurisdicional), começaram a fazer parte da esfera do poder visível —, mas também através da gestão dos grandes centros de poder econômico (bancos, indústrias estatais, indústrias subvencionadas, etc.), da qual acima de tudo extrai 
os meios de subsistência dos aparatos dos partidos, dos aparatos dos quais por sua vez extrai, através das eleições, a própria legitimação para governar. (BOBBIO, 1997, p. 103)

A análise da crise funcional pode ser feita sob o ponto de vista interno, relativo à clássica tripartição de poderes, mas, especialmente, sob a análise das investidas externas e contra o Estado. Os poderes extraestatais assumem, através do poder econômico e de formação de consenso, funções classicamente atribuídas ao Estado, privatizando, assim, a esfera pública.

A crise política, ou de representação, diz respeito aos golpes sofridos pela democracia, especialmente graças ao segundo processo desconstituinte. $\mathrm{O}$ enfraquecimento do regime democrático ocorre através do que Pierre Rosanvallon (2010, p. 29) ${ }^{9}$ denomina “[...] movimento global de descentralização das democracias”. Para ele, a estrutura da democracia representativa fundada nas eleições não foi capaz de conter o crescimento demandado pela sociedade, o que resultou na precarização da representatividade democrática ou, até mesmo, nas palavras de Luigi Ferrajoli (2011), numa involução populista da democracia representativa. Essa crise de representatividade está intimamente ligada à crise da dimensão constitucional da democracia, sendo possível falar até mesmo de uma crise geral do Estado democrático de direito. (BOLZAN DE MORAIS, 2002)

Os modelos de crises também podem ser interpretados de acordo com a origem dos poderes selvagens invisíveis que as causam. Luigi Ferrajoli (2011) faz a distinção entre "crisis por arriba" (descendentes) e “crisis por abajo" (ascendentes).

A crise "por cima" é o resultado da ação de quatro fatores: populismo, confusão e concentração de poderes, integração dos partidos políticos ao Estado e ausência de garantias de informação, os quais, apesar de aparentemente opostos, convergem para minar a relação de representação

9 Para que se evite mixagens teóricas indevidas, é necessário ressaltar que não se compactua neste artigo com as afirmações sobre a crise da democracia representativa da maneira como foram colocadas por Rosanvallon (2010). 
política vigente e para negar as separações entre as diversas esferas de poder caracterizadoras do Estado constitucional. Assim, resultam nas “[...] regresiones premodernas y, lo que es más grave, en el desarrollo de otros tantos poderes desregulados y salvajes". (FERRAJOLI, 2011, p. 45)

O controle da informação, fator da crise "por cima" que interessa ao presente estudo, está diretamente vinculado aos poderes midiáticos e à concentração dos meios de comunicação de massas. Não se fala aqui da liberdade de expressão e comunicação como vínculo negativo, mas positivamente, como liberdade real para o pluralismo dentro das media, onde, atualmente, os direitos fundamentais estão subordinados por fatores econômicos. Isso, nas palavras de Ferrajoli (2011, p. 62), faz com que o pensamento, a opinião e a informação sejam considerados não como direitos fundamentais, mas como mercadorias, bens patrimoniais regidos pela dinâmica do mercado e da política. A liberdade de expressão e comunicação não pode ser confundida com a liberdade de propriedade dos donos das media.

A "crise por baixo" é aquela relativa à representação, reflexo da "crise por cima" na população. Fundamenta-se na ilusão de que a maioria dispõe ilimitadamente do sistema jurídico quando, na verdade, sua vontade pode ser facilmente moldada pelos poderes políticos e midiáticos, especialmente nas sociedades que subvalorizam o pluralismo político, a liberdade de expressão e comunicação e os direitos fundamentais. Pode ser dividida em quatro "sintomas" (FERRAJOLI, 2011, p. 65), consequências diretas das "crises por cima": a homologação dos que consentem e a exclusão dos dissidentes; a despolitização massiva e a dissolução da opinião pública; a diminuição da participação e interesse na política; a manipulação da informação e a decadência da moral pública.

De maneira geral, essas crises resultam na fragilização da relevância política da opinião pública. A dissolução da esfera pública política, como visto, impossibilita a formação de uma legítima opinião pública. Promove-se, através da mentira incivil (FERRAJOLI, 2011) propagada pelas media, o desinteresse e a indiferença das massas em relação aos assuntos políticos. Os indivíduos, agora preocupados unicamente com as respectivas esferas privadas, têm seus laços sociais enfraquecidos, o que 
permite que a opinião pública seja corrompida e transformada em consenso de massas pelo poder midiático.

\section{Conclusões}

Conforme foi visto, a análise dos fatores que podem levar à desintegração da esfera pública política, tais como a existência de uma opinião pública simulada, certamente não é fenômeno novo, tampouco é a existência de poderes invisíveis. A problemática novidade surge por um duplo fator: a ocorrência dessas situações na democracia constitucional e a disponibilização de meio tecnológico abundante pelos meios de comunicação de massas. Essas novidades sustentam algumas das diversas crises que abalam o Estado contemporâneo.

A democracia não é compatível com poderes invisíveis e/ou "selvagens", como quer Ferrajoli, que atuam à margem da lei e do controle do poder. Assim, procurou-se identificar os fundamentos teóricos de tal incompatibilidade e demonstrar a existência desses poderes que, incontrolados, dissolvem a estrutura constitucional e, portanto, os direitos fundamentais.

Frutos de um frágil equilíbrio, os direitos fundamentais exigem a separação dos poderes e a transparência no seu exercício. Se, no passado, a separação clássica de poderes foi suficiente para proteger os direitos fundamentais, o mesmo não ocorre na atualidade. O surgimento de forças paralelas ao Estado impõe a necessidade de uma teoria jurídica que estabeleça limites também para esses novos poderes. Uma delas, a midiática, pode desenvolver alianças pouco democráticas com os poderes econômico e político. Assim, os levantamentos sobre a concentração de propriedade dos meios de comunicação de massas e sua relação com os detentores do poder político no Brasil podem causar espanto, não pela novidade, mas pela verdade que colocam.

A manipulação da informação transformou as media em fábricas de consenso sujeitas ao controle dos seus proprietários. Essas fábricas, em virtude do problema da concentração proprietária, são poucas e politicamente vinculadas, possibilitando, assim, a filtragem, invenção, distorção 
e manipulação das notícias que chegarão ao público. O debate social, já nasce, portanto, viciado, pois alimentado com informações igualmente viciadas. Indo um pouco mais longe, se for considerada a importância da televisão como fonte de educação de crianças e informação de adultos, é possível afirmar que ocorre manipulação da própria consciência do cidadão. Obviamente, não existe um direito à informação verdadeira, mas somente o direito de receber informações. No entanto, é possível falar, dentro do conceito de liberdade de expressão e comunicação, no direito de não ser deliberadamente desinformado e manipulado ou, para utilizar a analogia feita por Ferrajoli entre as media e as fábricas de informações, o direito de não receber "mercadorias" viciadas.

A relação entre as crises do Estado e a constatação dos meios de comunicação de massas como poderes invisíveis e selvagens traz à superfície a urgente necessidade de regulamentação do setor no sentido - mas não necessariamente na forma - das propostas feitas recentemente pelo Poder Executivo brasileiro. Não se trata, como querem acreditar alguns, de censura, mas do ideal democrático de controle do poder. Afinal, não há pluralismo sem que seja permitida a efetiva participação do cidadão na formação da comunicação política através dos meios de comunicação de massas e não se pode falar em democracia representativa sem que seja garantido o livre e consciente exercício do voto. A atual situação inverte a lógica dos direitos fundamentais e deixa a liberdade de expressão e comunicação sob o controle do poder econômico. Os discursos pela "liberdade de expressão" que se opõem ao controle dos meios de comunicação de massas são, na realidade, discursos pela "liberdade dos proprietários", o mesmo tipo de discurso que coloca, segundo a Freedom House, o Brasil na $97^{\text {a }}$ posição do Global press freedom ranking 2011.

É preciso, na luta pelos direitos fundamentais, identificar os problemas que causam a crise do Estado e possibilitar o aparecimento de uma resistência teórica capaz de lidar com o surgimento e consolidação dessa nova e ainda incontrolada forma de poder, concentrada em mãos privadas e possuidoras de um enorme aparato tecnológico de comunicação social. 


\section{Referências}

BOBBIO, Norberto. A democracia e o poder invisível. In: . futuro da democracia. 6. ed. Tradução de Marco Aurélio Nogueira. Rio de Janeiro: Paz e Terra, 1997. p. 41-64.

. Democracia representativa e democracia direta. In:

futuro da democracia. 6. ed. Tradução de Marco Aurélio Nogueira. Rio de Janeiro: Paz e Terra, 1997. p. 83-106.

. Pluralismo. In: BOBBIO, Norberto; MATTEUCCI, Nicola; PASQUINO, Gianfranco. Dicionário de política. 11. ed. Tradução de Carmen C. Varriale et al. 11. ed. Brasília: UnB, 1998. (p. 928-933) BOLZAN DE MORAIS, José Luis. A subjetividade do tempo: uma perspectiva transdisciplinar do Direito e da Democracia. Porto Alegre: Livraria do Advogado, 1998. (124p.)

. As crises do Estado e da Constituição e a transformação espacial dos direitos humanos. Porto Alegre: Livraria do Advogado, 2002. (104p.)

BOLZAN DE MORAIS, José Luis; STRECK, Lenio L. Ciência política e teoria do estado. 7. ed. Porto Alegre: Livraria do Advogado, 2010. (211p.)

CHOMSKY, Noam; HERMAN, Edward. S. Contendo a democracia. Tradução de Vera Ribeiro. Rio de Janeiro: Record, 2003. 516p. (393p.)

. Manufacturing Consent. New York: Pantheon Books, 1988.

FERRAJOLI, Luigi. Democracia y garantismo. Tradução de Perfecto Andrés Ibáñez et al. Madrid: Trotta, 2008. (373p.)

. Derecho y razón: teoría del garantismo penal. Tradução de Perfecto Andrés Ibáñez. Madrid: Trotta, 1995. 991p. 
. II processo decostituente. Critica marxista: analisi e contributi per ripensare la sinistra, Rioja, Espanha, n. 6, p. 9-19, 2005.

. Il processo decostituente: depoimento. [21 de outubro de 2010]. Roma: Scuola per la Buona Politica di Torino. Entrevista concedida a Michelangelo Bovero. Disponível em: $<$ http://www. sbptorino.org>. Acesso em: 10 dez. 2011.

. Poderes salvajes: la crisis de la democracia constitucional. Trad. Perfecto Andrés Ibáñez. Madrid: Trotta, 2011. (109p.)

. Principia iuris: teoria del diritto e della democrazia 1. Teoria del diritto. Bari: Laterza, 2007a. v. 1. (1.021p.)

. Principia iuris: teoria del diritto e della democrazia. Bari:

Laterza, 2007b. v. 2. 713p. (Teoria della democrazia 2)

HABERMAS, Jürgen. Mudança estrutural da esfera pública: investigações quanto a uma categoria da sociedade burguesa. Trad. Flávio R. Kothe. Rio de Janeiro: Tempo Brasileiro, 2003. (398p.)

. Strukturwandel der öffentlichkeit: untersuchungen zu einer kategorie der bürgerlichen gesellschaft. Frankfurt: Suhrkamp, 1990. (391p.)

. The structural transformation of the public sphere: an inquiry into a category of bourgeois society. Trad. Thomas Burger. Cambridge: The MIT Press, 1993. (301p.)

IBÁÑEZ, Perfecto Andrés. Prólogo. In: FERRAJOLI, Luigi. Poderes salvajes: La crisis de la democracia constitucional. Trad. Perfecto Andrés Ibáñez. Madrid: Trotta, 2011. (p. 9-17)

KANT, Immanuel. Para a paz perpétua. Trad. de Bárbara Kristensen. Rianxo: Instituto Galego de Estudos de Segurança Internacional e da Paz, 2006. (116p.)

LIPMAN, Maria. Freedom of expression without freedom of the press. Journal of International Affairs, New York, v. 62, n. 2, p. 153-169, Spring/Summer, 2010. 
MATTEUCCI, Nicola. Opinião Pública. In: BOBBIO, Norberto; MATTEUCCI, Nicola; PASQUINO, Gianfranco. Dicionário de política. 11. ed. Tradução de Carmen C. Varriale et al. Brasília: UnB, 1998. p. 842-845.

MONTESQUIEU, Charles de Secondat, Baron de. O espírito das leis. Trad. Cristina Murachco. São Paulo: Martins Fontes, 1996. (851p.) PANEBIANCO, Angelo. Comunicação Política. In: BOBBIO, Norberto; MATTEUCI, Nicola; PASQUINO, Gianfranco. Dicionário de política. Tradução de Carmen C. Varriale et al. 11. ed. Brasília: UnB, 1998. (p. 200-204)

ROSANVALLON, Pierre. La legitimidad democrática: imparcialidad, reflexividad y proximidad. Trad. Heber Cardoso. Barcelona: Paidós, 2010. (317p.)

SANI, Giacomo. Consenso. In: BOBBIO, Norberto; MATTEUCI, Nicola; PASQUINO, Gianfranco. Dicionário de política. 11. ed. Tradução de Carmen C. Varriale et al. Brasília: UnB, 1998. (p. 240-242) SARTORI, Giovani. Homo videns: la sociedad teledirigida. Trad. Ana Díaz Soler. Buenos Aires: Taurus, 1998. (159p.)

TAYLOR, Charles. Uma era secular. Trad. Nélio Schneider e Luzia Araújo. São Leopoldo: UNISINOS, 2010. (930p.)

THOMSON, John B. Comunicação de massa. In: OUTHWAITE, William; BOTTOMORE, Tom. Dicionário do pensamento social do século XX. Trad. Eduardo Francisco Alves e Álvaro Cabral. Rio de Janeiro: Zahar, 1996.

. Los media y la modernidad: una teoría de los medios de comunicación. Tradução de Jordi Colobrans Delgado. Barcelona: Paidós, 1998. (357p.) 
Daniela Mesquita Leutchuk de Cademartori é Doutora e Mestre em Direito pela Universidade Federal de Santa Catarina (UFSC). Possui Pós-Graduação (lato sensu) em Fundamentos de Epistemologia pela Universidade de Santa Cruz do Sul (UNISC) e Graduação em Direito e em História pela Universidade Federal de Santa Maria (UFSM). Docente do Centro Universitário La Salle (Unilasalle Canoas - RS) e professora vinculada ao Projeto de Mestrado Direito e Sociedade da Unilasalle de Canoas - RS. E-mail: daniela_cademartori@yahoo.com.br. Endereço profissional: Centro Universitário La Salle. Av. Victor Barreto, 2288, CEP: 92.010-000. Centro, Canoas/RS.

Elias Jacob de Menezes Neto é Doutorando e Mestre em Direito pela Universidade do Vale do Rio dos Sinos (UNISINOS) e Graduado em Direito pela Universidade Federal do Rio Grande do Norte (UFRN).E-mail: ejmneto@me.com.

Endereço profissional: Universidade do Vale do Rio dos Sinos. Programa de Pós-Graduação em Direito. Av. Unisinos, 950, CEP: 93.022-000. Cristo Rei, São Leopoldo/RS. 